\title{
Correction to: Psychological and somatic distress in Chinese outpatients at general hospitals: a cross-sectional study
}

Nana Xiong ${ }^{1}$, Jing Wei ${ }^{1 *} \mathbb{D}$, Kurt Fritzsche ${ }^{2}$, Rainer Leonhart ${ }^{3}$, Xia Hong ${ }^{1}$, Tao Li ${ }^{1}$, Jing Jiang ${ }^{1}$, Liming Zhu ${ }^{4}$, Guoqing Tian ${ }^{5}$, Xudong Zhao ${ }^{6}$, Lan Zhang ${ }^{7}$ and Rainer Schaefert ${ }^{8}$

\section{Correction to: Ann Gen Psychiatry (2017) 16:35 https://doi.org/10.1186/s12991-017-0158-y}

Unfortunately, after publication of this article [1], it was noticed that the affiliation of Rainer Schaefert is incorrectly displayed as, "Department of General Internal Medicine and Psychosomatics, University Hospital Heidelberg, Heidelberg, Germany". The correct affiliation should read, "Department of Psychosomatics, Medical Division, University Hospital Basel, Basel, Switzerland" and can be seen in the author details of this correction.

\section{Author details}

${ }^{1}$ Department of Psychological Medicine, Peking Union Medical College Hospital, Chinese Academy of Medical Sciences \& Peking Union Medical College, Beijing 100730, People's Republic of China. ${ }^{2}$ Department of Psychosomatic Medicine and Psychotherapy, University Medical Centre Freiburg, Freiburg, Germany. ${ }^{3}$ Institute of Psychology, University of Freiburg, Freiburg, Germany. ${ }^{4}$ Department of Gastroenterology, Peking Union Medical College Hospital, Chinese Academy of Medical Sciences \& Peking Union Medical College, Beijing, China. ${ }^{5}$ Department of Traditional Chinese Medicine, Peking Union Medical College Hospital, Chinese Academy of Medical Sciences \& Peking Union Medical College, Beijing, China. ${ }^{6}$ Department of Psychosomatic Medicine, Dongfang Hospital, School of Medicine, Tongji University, Shanghai, China.
${ }^{7}$ Mental Health Centre, West China Hospital, Sichuan University, Chengdu, Sichuan, China. ${ }^{8}$ Department of Psychosomatics, Medical Division, University Hospital Basel, Basel, Switzerland.

The original article can be found online at https://doi.org/10.1186/ s12991-017-0158-y.

\section{Publisher's Note}

Springer Nature remains neutral with regard to jurisdictional claims in published maps and institutional affiliations.

Received: 25 January 2018 Accepted: 25 January 2018

Published online: 05 February 2018

\section{Reference}

1. Xiong N, Wei J, Fritzsche K, Leonhart R, Hong X, Li T, Jiang J, Zhu L, Tian G, Zhao X, Zhang L, Schaefert R. Psychological and somatic distress in Chinese outpatients at general hospitals: a cross-sectional study. Ann Gen Psychiatry. 2017;16:35. https://doi.org/10.1186/s12991-017-0158-y.

\footnotetext{
${ }^{*}$ Correspondence: weijing@pumch.cn

${ }^{1}$ Department of Psychological Medicine, Peking Union Medical College Hospital, Chinese Academy of Medical Sciences \& Peking Union Medical College, Beijing 100730, People's Republic of China

Full list of author information is available at the end of the article
}

(0) The Author(s) 2018. This article is distributed under the terms of the Creative Commons Attribution 4.0 International License (http://creativecommons.org/licenses/by/4.0/), which permits unrestricted use, distribution, and reproduction in any medium, provided you give appropriate credit to the original author(s) and the source, provide a link to the Creative Commons license, and indicate if changes were made. The Creative Commons Public Domain Dedication waiver (http://creativecommons.org/ publicdomain/zero/1.0//) applies to the data made available in this article, unless otherwise stated. 